\title{
Influence of allelic prolamin variation and localities on durum wheat quality
}

\author{
Elyes Babay ， Mohsen Hanana , Rim Mzid , Hajer Slim-Amara , Jose M. Carrillo , \\ Marta Rodríguez-Quijano
}

Keywords:

Durum wheat

Glutenins

Gliadins

Gluten quality

\begin{abstract}
A B S T R A C T
Thirty-seven varieties of a Mediterranean durum wheat collection grown in Tunisia and Spain were analysed for their allelic composition in prolamins, as well as their protein concentration, sodium dodecyl sulphate sedimentation (SDSS) test and mixograph parameters. Genotype was a greater source of variation in all measurements than locality. Uncommon high and low molecular glutenin subunits (HMW-GS and LMW-GS) were found (V and 2ø subunits at Glu-A1,13 + 16 at Glu-B1, 5* subunit and ax allele at Glu-A3). The rare combinations $2+4+14+18$ and $8+9+13+16+18$ subunits at the Glu-B3 locus were found. Glu-A3ax had a positive influence on SDSS and mixograph parameters. Of all the

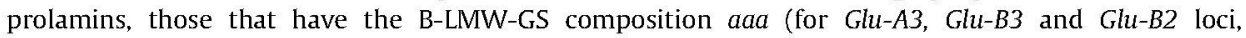

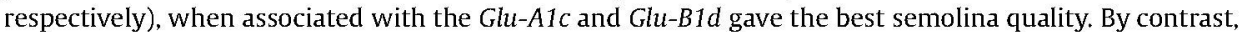
semolina quality is poor when this same composition is associated with the Glu-A1c and Glu-B1e and even poorer when associated with the Glu-A1c and Glu-B1f. In addition, the cultivars with B-LMW-GS allelic composition $a a b$ (for Glu-A3, Glu-B3 and Glu-B2 loci, respectively), when associated with the GluA1c and Glu-B1d, gave high quality, whereas when associated with the Glu-A1c and Glu-B1e or with Glu$A 10$ and Glu-B1f, the quality was very poor.
\end{abstract}

\section{Introduction}

Durum wheat (Triticum turgidum L.ssp. durum (Desf.)) is the preferred raw material for the production of pasta worldwide and couscous in North Africa and the Mediterranean region. Semolina/ flour protein content and gluten composition are the main factors that determine the quality of durum wheat cultivars and pasta cooking quality (DuCros, 1987). Environment and potential interaction between environment and genotype are also important

Abbreviations: BDR, Breakdown Resistance; HMW-GS, High Molecular Weight Glutenin Subunits; LMW-GS, Low Molecular Weight Glutenin Subunits; MT, Mixing Time; SDSS, Sodium Dodecyl Sulphate Sedimentation. factors influencing the durum wheat grain quality parameters (Lerner et al., 2004).

The genetic improvement of protein content has been particularly hampered, not only by strong environmental influences, but also by the fact that a negative correlation has frequently been found between grain yield and seed protein content in segregating populations in all cereals (Marchylo et al., 2001). Two types of gluten protein: gliadin and glutenin (prolamins), have been studied to establish their relationships with pasta quality. In durum wheat, prolamins are coded by complex loci located in chromosomes of homeologous groups 1 and 6 . The loci coding for the high molecular weight glutenin subunits (HMW-GS) are located on the long arms of chromosomes $1 \mathrm{~A}$ and $1 \mathrm{~B}$ and are called Glu-A1 and Glu-B1, respectively (Payne et al., 1982), and the loci coding for the low molecular weight glutenins (LMW-GS) are located on the short arms of the same chromosomes (Singh and Shepherd, 1988), and are called Glu-A3 and Glu-B3, respectively. Closely linked to these, the loci $G l i-A 1$ and $G i-B 1$ encode the $\omega$ - and some $\gamma$-and $\beta$-gliadins (Singh and Shepherd, 1988). The loci Gli-A2 and Gli-B2 encode some 
$\gamma_{-}, \beta-$, and $\alpha$-gliadins and are located on the short arms of $6 \mathrm{~A}$ and $6 \mathrm{~B}$ chromosomes, respectively. Other minor loci involved in the expression of LMW-GS: Glu-B2 and Glu-B4, have also been identified (Ruiz and Carrillo, 1993).

Previous studies have used the $\gamma$-gliadins 45 and 42 as markers for good and poor gluten quality, respectively (DuCros et al., 1982.) This is due to the genetic linkage with LMW-GS (Payne et al., 1984). In fact, pasta cooking quality and gluten strength were initially related to the negative and positive effects of the low molecular glutenin subunit patterns LMW-1 and LMW-2, respectively (Payne et al., 1984). The HMW-GS appear to have less critical effects than the LMW-GS on the gluten strength of durum wheat (Vázquez et al., 1996), but this has not been clearly established because of limited genetic variability at the Glu-1 loci present in modern durum wheat cultivars used in published studies (Sissons et al., 2005). In this context, some studies have shown the existence of variability and new alleles for quality traits in durum wheat landraces (Aguiriano et al., 2008) and in related species (Sissons and Batey, 2003).

Combinations of SDS-sedimentation test, mixograph parameters and protein content have been found to be good predictors of cooked pasta quality (Dick and Quick, 1983). The primary objective of the work presented here was to use these tests to evaluate Mediterranean durum wheat cultivars and landraces for pasta quality in field trials sown in Tunisia and Spain to determine the influence of the environment on gluten strength. Secondary objectives were to analyse the variability and the genetic control of HMW-GS and B-LMW-GS in the cultivars in order to determine the allelic variation at each of the loci involved and to study any new alleles found and evaluate the effect of allelic variation on gluten strength.

\section{Materials and methods}

\subsection{Plant materials}

Thirty-seven old and modern durum wheat cultivars from Mediterranean countries (two from Italy, twenty two from Spain and thirteen from Tunisia) were collected (Table 1). All genotypes were sown in a randomized complete-block design with two replicates per genotype during the 2010-2011 season at two localities: Experimental Station of the Center of Biotechnology (Borj-Cédria, Tunisia) $\left(36^{\circ} 42^{\prime} \mathrm{N}, 10^{\circ} 28^{\prime} \mathrm{E}\right)$ and the Agronomy Engineers School Experimental Station (Madrid, Spain) $\left(40^{\circ} 25^{\prime} \mathrm{N}, 3^{\circ} 42^{\prime} \mathrm{W}\right)$. In this site the soil was a well-drained Typic Xerorthents, with a sandy loam texture. The mineral fertilization was applied once in presowing, $350 \mathrm{Kg} / \mathrm{Ha}$ of $9 \mathrm{~N}, 18 \mathrm{P}_{2} \mathrm{O}_{5}, 27 \mathrm{~K}_{2} \mathrm{O}$. Throughout the growing season (November through July), the natural rainfall received $28,78,41,30,50,57,61,29,0 \mathrm{~mm}$ of water, respectively. The monthly average air temperature ranged from $6.2{ }^{\circ} \mathrm{C}$ in December to $25.1^{\circ} \mathrm{C}$ in July. The Experimental Station is located in northern Tunisia and belongs to the semi-arid bioclimatic stage. The soil is loamy-clay classified as Xerofluvent. A mineral fertilization was applied, in pre-sowing for phosphorus $\left(60 \mathrm{~kg}\right.$ of $\mathrm{P}_{2} \mathrm{O}_{5}$ per ha) and post-sowing nitrogen (100 kg of ammonitrate at $33.5 \%$ $(\mathrm{N})$ ) with two fractions (lifting and tillering). The natural rainfall was $45,50,59,34,38,27,16,8 \mathrm{~mm}$ of water during November to June, respectively. The site had air temperature that ranged from $8.4 \mathrm{C}^{\circ}$ in January to $26.8 \mathrm{C}^{\circ}$ in June.

\subsection{Electrophoretic analysis}

Glutenins were extracted using a sequential procedure (Singh et al., 1991). Electrophoresis of reduced and alkylated proteins (HMW-GS and LMW-GS) was performed on SDS-PAGE (12\% polyacrylamide) (Payne et al., 1980). Gliadins were fractionated by A-
PAGE (Lafiandra and Kasarda, 1985). HMW-GS alleles at Ghu-1 loci were identified using the nomenclature of Payne and Lawrence (1983). B-LMW-GS alleles at Glu-3 and Glu-2 loci were identified as described by Nieto-Taladriz et al. (1997).

\subsection{Quality evaluation}

A sample of grain was randomly taken from each replicate, cleaned and used for the determination of quality, therefore, four values for each quality test of the analyzed variety were obtained. Some of the varieties did not have material of the two repetitions of both locations. Three values of each quality parameter were recorded for the varieties: Chili, Clarofino de Balazote, Derbessi, Inrat69, Mahmoudi, Richi and Swabaa Algia, whereas, only two values were obtained for Farto and Recio Cañihueco. Protein content, on a $14 \%$ moisture basis, was estimated by near-infrared reflectance analysis (NIR) using a Technicon Infralyzer 300 Gluten strength was estimated by the SDS-sedimentation (SDSS) test according to Dick and Quick (1983). Rheological properties were determined by Mixograph of $10 \mathrm{~g}$ whole wheat meal (Finney and Shogren, 1972). The mixograph parameters measured were: mixing development time (MT), maximum peak height (MH), height at 3 min after the peak (H3), and resistance to breakdown (BDR) (percentage difference between $\mathrm{MH}$ and $\mathrm{H} 3$ ). The high values of SDSS and MT and lower of BDR were accorded to good quality.

\subsection{Statistical analyses}

The growing environment and allelic variation at each locus were considered as sources of variation. The data were analysed using SAS statistical software (SAS institute, Cary, NC). ANOVA and differences between mean values were analysed using the Duncan method for multiple comparisons at $P=0.05$. PROC GLM and PROC MIXED were used to accommodate the unbalanced data. Pearson correlation coefficients were calculated to determine the relationships between mean values of the test results.

\section{Results and discussion}

\subsection{Electrophoresis for prolamin composition}

The electrophoretic analysis of prolamins carried out on five grains of each cultivar gave identical patterns for each one of the 37 cultivars. Electrophoretic analysis of the prolamins was also carried out on the same gel for the two replicates of each cultivar from the two localities in order to determine flour homogeneity. Table 1 shows the composition of the 37 cultivar prolamins analysed and Fig. 1 shows the composition of some cultivar prolamins.

\subsubsection{HMW-GS (Glu-A1/Glu-B1)}

Five different HMW subunits encoded by the Glu-A1 locus were found (Table 1). These were the $1,2^{*}$ and Null subunits $(a, b$ and $c$ alleles, respectively, according to Payne and Lawrence (1983)) and two rare subunits (V and $2 \bullet \bullet$ ). The V subunit (allele 0 ) was only found in two landraces and the 2.* subunit (allele $y$ ) was only found in one Spanish landrace (Table 1). The most frequent subunit found was the Null subunit, while the 1 and $2^{*}$ subunits were only found in Spanish landraces. The high frequency of the Null glutenin subunit of the Glu-A1 locus has also been described in other studies of durum wheat from Mediterranean countries (Carrillo et al., 1990; Cherdouh et al., 2005; Nazco et al., 2014). The rare subunit V has been found previously in landraces of durum wheat and Triticum dicoccum (Vallega and Mello-Sampayo, 1987) and Triticum turanicum (Rodriguez-Quijano et al., 2010). The 2•• subunit was observed in some bread wheat genotypes (Giraldo et al., 2010). 
Table 1

$\gamma$-Gliadin, HMW-GS and B-LMW-GS compositions for the 37 durum wheat varieties analysed.

\begin{tabular}{|c|c|c|c|c|c|c|}
\hline \multirow{2}{*}{$\frac{\text { Gliadins }}{\text { Gli-B1 }}$} & \multicolumn{2}{|c|}{ Subunits and allele of HMW-GS } & \multicolumn{3}{|c|}{ Alelle and some subunits of B-LMW-GS } & \multirow[t]{2}{*}{ Varieties } \\
\hline & Glu-A1 & Glu-B1 & Glu-A3 & Glu-B3 & Glu-B2 & \\
\hline$\gamma-45$ & Null (c) & $20 x+20 y(e)$ & $a$ & $a$ & $\mathfrak{a}$ & $\begin{array}{l}\text { Amorós Blanco }^{(\mathrm{SL})} \text {; Chili }{ }^{(\mathrm{TL})} ; \text { Clarofino de Balazote }^{(\mathrm{SL})} \\
\text { Horcajo }^{(\mathrm{SL})} \text {; Inrat } 69^{(\mathrm{TL})} ; \text { Mahmoudi }^{(\mathrm{TL})} \text {; Raspinegro } \\
\text { Recio de }^{(\mathrm{SL})} \text {; }\end{array}$ \\
\hline$\gamma-45$ & Null (c) & $7+8(b)$ & $a$ & $a$ & $a$ & Khiar $^{(\mathrm{TC})} ;$ Maali( $^{(\mathrm{TC})} ; \mathrm{Nasr}^{(\mathrm{TC})}$ \\
\hline$\gamma-45$ & Null (c) & $13+16(f)$ & $a$ & $a$ & $a$ & Om Rabii ${ }^{(\mathrm{TC})}$ \\
\hline$\gamma-45$ & Null (c) & $13+16(f)$ & $a$ & $2,4,14,18$ & $b$ & Biskri $^{(\mathrm{TL})}$ \\
\hline$\gamma-45$ & $V(o)$ & $6+8(d)$ & $a$ & $2,4,14,18$ & $b$ & Baidha ${ }^{(\mathrm{TL})}$ \\
\hline$\gamma-45$ & Null (c) & $20 x+20 y(e)$ & $a$ & $2,4,14,18$ & $b$ & Swabaa Algia ${ }^{(T L)}$ \\
\hline$\gamma-45$ & $1(a)$ & $20 \mathrm{x}+20 \mathrm{y}(e)$ & $a$ & $a$ & $b$ & Blat Fort ${ }^{(S L)}$ \\
\hline$\gamma-45$ & Null (c) & $6+8(d)$ & $a$ & $a$ & $b$ & Derbessi $^{(\mathrm{TL})}$; Grécale ${ }^{(\mathrm{IC})}$; Recio Cañihueco ${ }^{(\mathrm{SL})}$; Recio de Bienservida ${ }^{(\mathrm{SL})}$ \\
\hline$\gamma-45$ & $2 \bullet(y)$ & $13+16(f)$ & $a$ & $a$ & $b$ & Pisana de vilanova ${ }^{(\mathrm{SL})}$ \\
\hline$\gamma-45$ & $2^{*}(b)$ & $6+8(d)$ & $h$ & $a$ & $a$ & Blanqueta $^{(\mathrm{SL})}$ \\
\hline$\gamma-45$ & $1(a)$ & $6+8(d)$ & $h$ & $a$ & $b$ & Claro de la Gineta ${ }^{(S L)}$ \\
\hline$\gamma-45$ & Null (c) & $6+8(d)$ & $h$ & $a$ & $a$ & Farto $^{(\mathrm{SL})}$; Villar de Cañas ${ }^{(\mathrm{SL})}$ \\
\hline$\gamma-45$ & $1(a)$ & $6+8(d)$ & $h$ & $a$ & $a$ & Pauleño de Mula ${ }^{\text {(SL) }}$ \\
\hline$\gamma-45$ & Null (c) & $20 x+20 y(e)$ & $h$ & $a$ & $a$ & Raspinegro Cañihueco de Calasparra ${ }^{\text {(SL) }}$ \\
\hline$\gamma-45$ & $2^{*}(b)$ & $6+8(d)$ & $h$ & $a$ & $b$ & Raspinegro Velloso ${ }^{(\mathrm{SL})}$ \\
\hline$\gamma-45$ & Null (c) & $6+8(d)$ & $a x$ & $a$ & $a$ & Iride $^{\text {(IC) }}$ \\
\hline$\gamma-45$ & $1(a)$ & $6+8(d)$ & $d$ & $f$ & $b$ & Rojo de Llerena ${ }^{\text {(SL) }}$ \\
\hline$\gamma-45$ & $V(0)$ & $6+8(d)$ & $d$ & $f$ & $b$ & Rubio Naranjuelo ${ }^{(\mathrm{SL})}$ \\
\hline$\gamma-42$ & Null (c) & $7+8(b)$ & $5^{*}$ & $8,9,13,16,18$ & $b$ & Candeal de Salamanca ${ }^{(S L)}$ \\
\hline$\gamma-42$ & Null (c) & $7+8(b)$ & $b$ & $b$ & $a$ & $\operatorname{Karim}^{(\mathrm{TC})}$ \\
\hline$\gamma-42$ & Null (c) & $6+8(d)$ & $5^{*}$ & $b$ & $b$ & Rubio Entrelago de Montijo ${ }^{(\mathrm{SL})}$ \\
\hline$\gamma-42$ & Null (c) & $6+8(d)$ & $5^{*}$ & $8,9,13,16,18$ & $b$ & Fanfarrón ${ }^{(S L)}$ \\
\hline$\gamma-44$ & Null (c) & $20 x+20 y(e)$ & $a$ & $a$ & $b$ & $\operatorname{Richi}^{(\mathrm{TL})}$ \\
\hline Null & $2^{*}(b)$ & d & $b$ & $i$ & $a$ & Valencia Blanco $^{(\mathrm{SL})}$ \\
\hline
\end{tabular}

(SL): Spanish Landrace; (TL): Tunisian Landrace; (TC): Tunisian Cultivar; (IC): Italian Cultivar.

On the other hand, Payne and Lawrence (1983) designated as $b$ and $d$, respectively, the locus Glu-B1 HMW-GS pairs observed in the bread wheat standard varieties 'Chinese Spring' $(7+8)$ and 'Hope' $(6+8)$. These authors considered that both By8 subunits had a similar SDS-PAGE mobility and therefore the same molecular weight. However, we have demonstrated that the subunit By8 of 'Chinese Spring' has a lower mobility in $12 \%$ polyacrylamide gels. Most of the durum wheat varieties examined present the same By8 subunit as the standard 'Chinese Spring' (Fig. 1). We have maintained the proposed designation of $d$ for pair $6+8$, though this allelic nomenclature clearly needs to be revised. Similarly, pair $20 \mathrm{x}+20 \mathrm{y}$ was initially designated as allele $e$ (Payne and Lawrence, 1983) but Margiotta et al. (1993) determined that corresponded to two closely linked subunits with distinct molecular weights. In addition to the mentioned pairs $6+8$ and $20 \mathrm{x}+20 \mathrm{y}$, GluB1 HMWGS $7+8$ and $13+16$ (alleles $b$, and $f$, respectively, according to Payne and Lawrence (1983)) have also been found. The high frequencies observed here for $6+8(45.9 \%)$ and $20 x+20 y(32.4 \%)$ have been reported for durum wheats from the Mediterranean region by other authors (Carrillo et al., 1990; Cherdouh et al., 2005; Nazco et al., 2014).

\subsubsection{B-LMW-GS (Glu-A3/Glu-B3/Glu-B2)}

Six different B-LMW-GS alleles, $a, b, d$ and $h$ (according to NietoTaladriz et al., 1997) and the $a x$ allele (according to Lerner et al., 2004), were detected at the Glu-A3 locus (Table 1), as well as the subunit $5^{*}$, previously reported as the New-7 allele (Aguiriano et al., 2008) found in the Spanish landrace 'Claro de Balazote'. In the present study, this subunit was found in three landraces of Spanish origin (Table 1). In Fig. 1, it can be seen that the subunit $5^{*}$ has a lower mobility than the subunit 5 of the standard 'Langdon' (NietoTaladriz et al., 1997). The $a x$ allele (subunit 6.1) has been described by Lerner et al. (2004) in the durum wheat cultivar 'Buck Cristal' from Argentina and has a higher mobility than the subunit 6 of the standard 'Mexicali' (Fig. 1). In our study, this subunit was found in the cultivar 'Iride' from Italy (Table 1). As shown in Table 1, the largest B-LMW-GS glutenin variability encoded by this locus (GluA3) was found in the Spanish landraces. The $a$ and $h$ alleles were the most frequently observed (59.5\% and $18.9 \%$, respectively) (Table 1 ). Similar occurrences of both alleles were reported previously by Cherdouh et al. (2005), who studied Algerian durum wheat landraces and old cultivars.

The Glu-B3 locus encoded four alleles $a, b, f$ and $i$ (as described by Nieto-Taladriz et al., 1997) and the $2+4+14+18$ and $8+9+13+16+18$ combinations of B-LMW subunits. The combination $(2+4+14+18)$ was found in three Tunisian landraces (Table 1 ). This combination of subunits was previously reported by Rodriguez-Quijano et al. (2010) in one Ethiopian accession of khorasan wheat (T. turanicum), and by Nazco et al. (2014) in two landraces of durum wheat. A second combination $(8+9+13+16+18)$ was found in two Spanish landraces (Table 1) and has previously been reported in two heterogeneous Algerian landraces (Cherdouh et al., 2005). Those authors described the landrace 'Richi' of Algerian origin and observed that the heterogeneous locus $G l u-B 3$ encoded the alleles $b / m$, with the $m$ allele having the subunits $8,9,13,16$ and 18 . In our study, the cultivar with the same name ('Richi') was observed to be homogeneous and possess the Glu-B3a allele, showing the heterogeneity that can exist in landrace varieties. The most frequent allele we found was the Glu-B3a allele (73\%); which is similar to the findings of Cherdouh et al. (2005), Aguiriano et al. (2008) and Nazco et al. (2014).

Two allelic variants encoded by the Glu-B2 locus: the $a$ and $b$ alleles (Nieto-Taladriz et al., 1997), were found with a similar frequency (Table 1).

\subsection{3. $\gamma$-Gliadins (Gli-B1 locus)}

We found four different $\gamma$-gliadin subunits encoded by the Gli$B 1$ locus (Table 1). Of the 37 genotypes, the Tunisian landrace 'Richi' had the rare $\gamma-44$ gliadin, previously described by Aguiriano et al. (2006) in Spanish landraces. One Spanish landrace had the null $\gamma$ gliadin and four cultivars have the $\gamma-42$ gliadin and the most frequent $\gamma$-gliadin was the $\gamma$-gliadin 45 (83.8\%) (Table 1). 

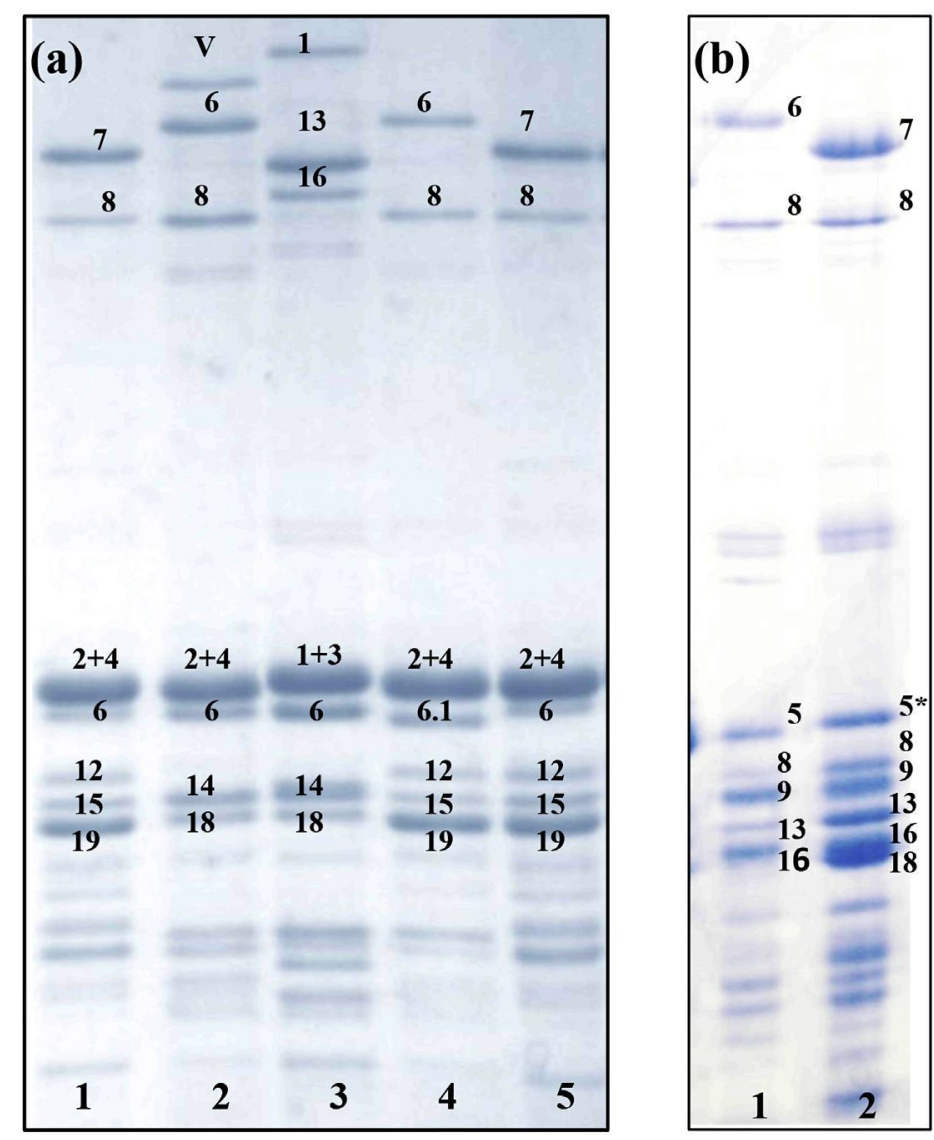

\section{HMW \\ Glutenin \\ subunits}

\section{B-LMW \\ Glutenin \\ subunits}

Fig. 1. SDS-PAGE fractionation of some uncommon HMW-GS and LMW-GS analysed. (a) Khiar(1), Baïdha(2), Alaga(3), Iride(4), Mexicali(5). (b) Langdon (1); Fanfarrón(2).

\subsection{Effect of prolamins on semolina quality}

The analysis of variance of each quality parameter was done using the genotype (prolamin composition), locality, replicate and their interactions as the sources of variation. This analysis identified the significant effect that the genotype has on the quality parameters and the significant interaction of genotype and location on the protein content and the mixograph breakdown parameter. Generally, durum wheat has higher protein content than bread wheat but a much lower quantity of protein, durum wheat tends to be much poorer in gluten strength (Liu et al., 1996).

The locality and replicate did not have a significant effect on the quality parameters. Table 2 shows the mean values of the quality parameters according to locality. The environment (locality) has been shown to exert a stronger influence over protein content than over other durum wheat quality parameters (Marchylo et al., 2001), may alter the composition of proteins during grain filling and influence gluten quality (Sissons et al., 2005). However, this was not the case in our study. The protein content was very similar for both localities, with a mean of $12.0 \%$ (Tables 2 and 3). Similarly, mean sedimentation volume and mixograph parameters differed only slightly between localities (Table 2). Moreover, a wide diversity in gluten quality evaluated by SDSS and mixograph parameters are observed in two localities (Table 2), especially between modern and old genotypes.

\subsubsection{Correlation between quality parameters}

There was a significant and positive correlation between protein content and mixograph BDR parameter $(r=0.43, P \leq 0.01)$ and between SDSS and mixograph MT parameter $(r=0.71, P \leq 0.01)$. The BDR parameter was significantly and negatively correlated to
SDS-sedimentation volume and MT parameter $(\mathrm{r}=0.45, \mathrm{P} \leq 0.01$ and $\mathrm{r}=0.43, \mathrm{P} \leq 0.01$, respectively). Thus, no correlation between protein content and SDS-sedimentation volume has been reported by our work and the studies of Vázquez et al. (1996). These results are in agreement with the fact that protein content is highly influenced by environmental conditions and crop management (cultural practices). In contrast, SDSS means values mainly depend on cultivar genotypes. The correlations between SDSS and the mixograph parameters are also consistent because both tests are related to the cultivar genotypes (Vázquez et al., 1996; Martinez et al., 2005).

\subsubsection{Quality effect of $B-L M W$-GS and $\gamma$-gliadin variation}

In initial studies on the relationship of gliadins to durum wheat quality, the presence of $\gamma-45$ in the flour of varieties was shown to be an indicator of good durum wheat quality, whereas the presence of $\gamma-42$ was shown to be an indicator of low durum wheat quality (DuCros et al., 1982). Later, Payne et al. (1984) observed a link between LMW glutenins and gluten quality in four wheat varieties and concluded that the variation in flour quality was not due to the $\gamma-45$ and $\gamma-42$ gliadins but was due to the LMW glutenins strongly linked to them on the short arm of chromosome $1 \mathrm{~B}$. However, they are easy to visualize in the A-PAGE electrophoresis gels, and then both gliadins ( $\gamma-42$ and $\gamma-45)$ can be used as indicators for a rapid quality analysis of the first generations of cultivar lines.

For the varieties that had the gliadins $\gamma-45$ or $\gamma-42$ and the allelic composition of loci Glu-A3, Glu-B3 and Glu-B2, we looked at the relationships between the quality parameters: SDSsedimentation volume (SDSS), mixing time (MT) and breakdown (\%) (Table 4). 
Table 2

Mean values ( \pm standard deviation) of the quality tests for the two different localities of the 37 durum wheat varieties analysed.

\begin{tabular}{|c|c|c|c|c|c|c|c|}
\hline Quality test & No. & Mean \pm sd & Range & Quality test & No. & Mean \pm sd & Range \\
\hline \multicolumn{4}{|c|}{ Locality: Borj Cedria (Tunisia) } & \multicolumn{4}{|c|}{ Locality: Madrid (Spain) } \\
\hline Protein (\%) & 71 & $12.0 \pm 1.2$ & $9.7-15.6$ & Protein & 64 & $11.9 \pm 1.0$ & $10.1-14.2$ \\
\hline SDSS (mm) & 72 & $36.0 \pm 15.2$ & $15.5-77.5$ & SDSS $(\mathrm{mm})$ & 65 & $32.8 \pm 12.2$ & $12.5-66.0$ \\
\hline $\mathrm{MT}(\mathrm{s})$ & 69 & $105.0 \pm 56.8$ & $20.5-283.8$ & $\mathrm{TM}(\mathrm{s})$ & 59 & $91.1 \pm 46.3$ & $23.1-218.1$ \\
\hline $\operatorname{BDR}(\%)$ & 69 & $23.3 \pm 9.5$ & $4.8-72.6$ & $\operatorname{BDR}(\%)$ & 59 & $22.8 \pm 6.9$ & $6.6-39.1$ \\
\hline
\end{tabular}

Abbreviation: SDSS $=$ Sodium dodecyl sulphate test; $\mathrm{MT}=$ Mixing time; BDR $=$ Breakdown resistance.

The ANOVA (Table 4) showed that there was a significant effect of the B-LMW-GS locus variation of the glutenins on the quality parameters when the gliadin $\gamma-45$ was present. The B-LMW-GS locus variation of the glutenins explained $17.8 \%, 39.8 \%$ and $19.0 \%$ of the variance of the quality parameters SDSS, MT and BDR, respectively. On the other hand, when the gliadin $\gamma-42$ was present, there was no significant effect of the alleles of B-LMW-GS on the quality parameters.

The multiple comparison (Duncan) of mean quality parameters (Table 4) showed that, when the gliadin $\gamma-45$ was present, the best allelic combination of the B-LMW-GS (Glu-A3, Gu-B3 and Glu-B2 loci) for high values of the quality parameters SDSS and MT and low values of BDR, was ax $a$ a (Table 4). The varieties with B-LMW-GS allelic combinations $a$ a $a$ and $a$ a $b$ (for the Glu-A3, Glu-B3 and Glu$B 2$ loci, respectively) also had good mean quality parameter values.
In durum wheat, the allelic combination aaa has been identified as a combination that gives high Gluten Index values (Sissons et al., 2005), whereas the contribution of the allele Glu-A3ax has not been determined until now. This allele, which was present in the Italian variety 'Iride', in conjunction with the alleles Glu-B3a and Glu-B2a, gave the highest mean quality parameter values of SDSS and MT and the lowest values of BDR (Table 4). The mean values of SDSS, MT and BDR were not significantly different for the varieties with these three B-LMW-GS allelic combinations (Glu-A3, Glu-B3 and Glu-B2) where the gliadin $\gamma-42$ was present: $5^{*} b b, 5^{*}$, $8,9,13,16,18 b$ and $b b a$. This is not surprising considering the results of the ANOVA, which did not identify any significant differences for these parameters.

Moreover, the allelic variation at the locus Glu-B2 was not expressed in the variation of quality parameters. There was no

Table 3

Grain protein content (at $14 \%$ humidity) of each variety in both localities.

\begin{tabular}{|c|c|c|c|c|}
\hline \multirow[t]{2}{*}{ Varieties } & \multicolumn{2}{|c|}{ Locality: Borj Cedria (Tunisia) } & \multicolumn{2}{|c|}{ Locality: Madrid (Spain) } \\
\hline & Means $\operatorname{Pr}(\%)$ & Range Pr $(\%)$ & Means $\operatorname{Pr}(\%)$ & Range $\operatorname{Pr}(\%)$ \\
\hline Amorós Blanco & 12.1 & $11.7-12.5$ & 12.1 & $11.7-12.5$ \\
\hline Baidha & 12.0 & $11.8-12.2$ & 13.5 & $12.8-14.2$ \\
\hline Biskri & 12.3 & $11.8-12.7$ & 13.7 & $13.5-13.9$ \\
\hline Blanqueta & 12.1 & $12.0-12.3$ & 12.5 & $11.2-13.8$ \\
\hline Blat Fort & 13.8 & $13.6-13.9$ & 12.7 & $12.0-13.4$ \\
\hline Chili & 13.2 & $12.5-13.9$ & 11.2 & $11.0-11.4$ \\
\hline Claro de la Gineta & 12.4 & $11.5-13.3$ & 13.7 & $13.6-13.9$ \\
\hline Clarofino de Balazote & 11.3 & $10.9-11.8$ & 11.6 & $11.3-12.0$ \\
\hline Candeal de Salamanca & 11.7 & $11.6-11.8$ & 12.5 & $11.9-13.1$ \\
\hline Derbessi & 11.1 & $11.0-11.3$ & 13.1 & $11.3-14.8$ \\
\hline Fanfarrón & 10.9 & $9.9-12.0$ & 12.2 & $11.9-12.4$ \\
\hline Grécale & 11.6 & $11.4-11.9$ & 11.8 & $11.7-11.8$ \\
\hline Horcajo & 13.8 & $13.7-14$ & 11.8 & $11.8-11.9$ \\
\hline Inrat69 & 12.0 & $11.6-12.4$ & 12.4 & $12.2-12.6$ \\
\hline Iride & 10.8 & $10.5-11.1$ & 11.8 & $11.7-12.0$ \\
\hline Karim & 11.2 & $11.0-11.3$ & 10.8 & $10.7-10.8$ \\
\hline Khiar & 10.8 & $10.6-10.9$ & 11.0 & $10.2-11.8$ \\
\hline Maali & 10.0 & $9.9-10.0$ & 11.4 & $11.3-11.4$ \\
\hline Mahmoudi & 12.1 & $11.6-12.5$ & 10.9 & $10.9-11.0$ \\
\hline Nasr & 11.4 & $11.3-11.6$ & 11.1 & $11.0-11.2$ \\
\hline Om Rabii & 11.3 & $11.3-11.4$ & 13.1 & $13.0-13.1$ \\
\hline Pauleño de Mula & 12.6 & $12.0-13.2$ & 11.6 & $11.2-11.9$ \\
\hline Pisana de Vilanova & 15.4 & $15.3-15.6$ & 10.4 & $10.3-10.4$ \\
\hline Raspinegro & 11.5 & $10.5-12.5$ & 11.6 & $11.2-12.1$ \\
\hline Raspinegro Cañihueco de Calasparra & 11.6 & $11.5-11.6$ & 11.5 & $11.4-11.5$ \\
\hline Raspinegro Velloso & 10.2 & $9.7-10.6$ & 12.0 & $11.2-12.7$ \\
\hline Raspinegro Cañihueco de Calasparra & 11.6 & $11.3-11.9$ & 11.5 & $11.4-11.5$ \\
\hline Recio Cañihueco & 12.3 & $11.4-13.3$ & 12.4 & $12.3-12.4$ \\
\hline Recio de Bienservida & 14.0 & $13.7-14.4$ & 12.9 & $12.6-13.3$ \\
\hline Recio de Cañete & 12.6 & $12.5-12.6$ & 11.8 & $11.5-12.0$ \\
\hline Richi & 12.5 & $12.3-12.6$ & 13.1 & $13.0-13.1$ \\
\hline Rojo de Llerena & 11.8 & $11.6-12.0$ & 10.2 & $10.1-10.3$ \\
\hline Rubio Entrelago de Montijo & 11.7 & $10.8-12.5$ & 12.6 & $11.8-13.4$ \\
\hline Rubio Naranjnuelo & 10.8 & $10.7-10.8$ & 10.4 & $10.3-10.5$ \\
\hline Swaba algia & 12.6 & $11.1-14.1$ & 13.0 & $12.8-13.2$ \\
\hline Valencia Blanco & 11.5 & $11.4-11.5$ & 12.0 & $11.9-12.1$ \\
\hline Villar de Cañas & 11.5 & $11.4-11.5$ & 11.8 & $11.2-12.4$ \\
\hline
\end{tabular}

Abbreviation: $\operatorname{Pr}(\%)=$ Protein content. 
Table 4

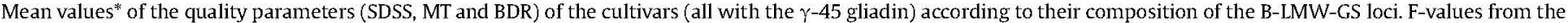
analysis of variance are given for the quality parameters.

\begin{tabular}{|c|c|c|c|c|c|c|}
\hline \multirow{2}{*}{$\begin{array}{l}\text { Gliadins } \\
\text { Gli-B1 }\end{array}$} & \multicolumn{3}{|c|}{ B-LMW-GS } & \multirow[t]{2}{*}{$\operatorname{SDSS}(\mathrm{mm})$} & \multirow[t]{2}{*}{ MT (s) } & \multirow[t]{2}{*}{$\mathrm{BDR}(\%)$} \\
\hline & Glu-A3 & Glu-B3 & $G l u-B 2$ & & & \\
\hline \multirow[t]{7}{*}{$\gamma-45$} & $a x$ & $a$ & $a$ & $62.1^{\mathrm{a}}$ & $237.7^{\mathrm{a}}$ & $11.8^{\mathrm{b}}$ \\
\hline & $a$ & $a$ & $b$ & $41.5^{\mathrm{b}}$ & $101.7^{\mathrm{b}}$ & $27.3^{a}$ \\
\hline & $a$ & $a$ & $a$ & $36.1^{\mathrm{b}}$ & $121.4^{\mathrm{b}}$ & $19.8^{a}$ \\
\hline & $d$ & $f$ & $b$ & $34.7^{\mathrm{b}}$ & $80.6^{\mathrm{bc}}$ & $25.7^{\mathrm{a}}$ \\
\hline & $h$ & $a$ & $a$ & $32.2^{\mathrm{b}}$ & $88.4^{\mathrm{bc}}$ & $22.5^{\mathrm{a}}$ \\
\hline & $h$ & $a$ & $b$ & $31.4^{\mathrm{b}}$ & $46.3^{c}$ & $27.5^{\mathrm{a}}$ \\
\hline & $a$ & $2,4,14,18$ & $b$ & $30.9^{b}$ & $84.2^{\text {bc }}$ & $24.7^{\mathrm{a}}$ \\
\hline ANOVA & & & & $3.85^{* *}$ & $10.98^{* *}$ & $3.91^{* *}$ \\
\hline \multicolumn{7}{|l|}{ F- $\gamma-45+$ B-LMW } \\
\hline F- $\gamma-42+$ B-LMW & & & & 0.52 & 0.45 & 0.34 \\
\hline
\end{tabular}

$\left({ }^{*}\right)=$ Mean values with the same letter are not significantly different $(\mathrm{p} \leq 0.05)$.

Abbreviation: SDSS $=$ Sodium dodecyl sulphate test; $M T=$ Mixing time; BDR $=$ Breakdown resistance.

significant differences between varieties with $a a a$ and $a a b$ composition (for Glu-A3, Glu-B3 and Glu-B2 loci, respectively), their behaviour is good. So the effect of Glu-B2a and Glu-B2b (Null) alleles would be similar, however Nazco et al. (2014) found that the Glu$B 2 a$ allele was associated with high SDS-values, while $G u$-B2 $b$ allele was highly frequent in varieties with medium and low SDS-values.

\subsubsection{Quality effect of B-LMW-GS, HMW-GS and $\gamma$-gliadins variation}

The subsequent analysis looked at the compositions of the $\gamma$ gliadins and the HMW and B-LMW glutenins of the varieties (Table 5). The HMW-GS composition has been shown to explain $60 \%$ of the variance of gluten strength in hexaploid bread wheats (Carrillo et al., 1990) while a much lesser influence has been considered in durum wheat quality (DuCros et al., 1982; DuCros, 1987). Nevertheless, Boggini and Pogna (1989) determined that the Glu-B1 genotype was more relevant for durum wheat gluten strength than Glu-A1 active (non-null) alleles, and further established the following order of importance for Glu-B1 alleles: $7+8>6+8>20$. Studies on Spanish landraces have proved that Glu-B1 alleles related with low quality in bread wheat contribute to good durum wheat quality, especially when compared with the influence of the $20 \mathrm{x}+20 \mathrm{y}$ subunit pair of the same locus (Martinez et al., 2005). Similar results were found with a set of Australian genotypes (Sissons et al., 2005). However, Nazco et al. (2014) reports a positive significant effect of Glu-B1 subunit $20 \mathrm{x}+20 \mathrm{y}$ in a wide collection of durum wheat landraces and modern cultivars from 21 Mediterranean countries.

The ANOVA of the quality parameters (Table 5) showed that there was a significant effect of the prolamins, explaining $60.3 \%$, $61.3 \%$ and $50.4 \%$ of the variance of the SDSS, MT and BDR parameters, respectively. Comparing this result with that above, which

Table 5

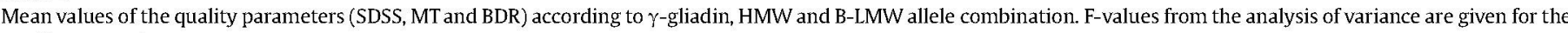
quality parameters.

\begin{tabular}{|c|c|c|c|c|c|c|c|c|c|}
\hline \multirow{2}{*}{$\frac{\text { Gliadins }}{\text { Gli-B1 }}$} & \multicolumn{2}{|c|}{ HMW-GS } & \multicolumn{3}{|c|}{ LMW-GS } & \multirow[t]{2}{*}{ No } & \multirow[t]{2}{*}{ SDSS (mm) } & \multirow[t]{2}{*}{ MT (s) } & \multirow[t]{2}{*}{ BDR (\%) } \\
\hline & Glu-A1 & Glu-B1 & Glu-A3 & Glu-B3 & Glu-B2 & & & & \\
\hline$\gamma-45$ & Null & $6+8$ & $\mathrm{ax}$ & $\mathbf{a}$ & $\mathrm{a}$ & 1 & $62.1^{\mathrm{a}}$ & $237.7^{\mathrm{a}}$ & $11.8^{\mathrm{e}}$ \\
\hline$\gamma-45$ & Null & $6+8$ & $a$ & $\mathrm{a}$ & $\mathrm{b}$ & 4 & $52.7^{\mathrm{ab}}$ & $131.7^{\mathrm{bc}}$ & $19.7^{\text {cde }}$ \\
\hline$\gamma-45$ & Null & $7+8$ & $\mathrm{a}$ & a & $\mathrm{a}$ & 3 & $47.8^{\mathrm{bc}}$ & $151.1^{\mathrm{b}}$ & $14.9^{\mathrm{de}}$ \\
\hline$\gamma-45$ & V & $6+8$ & $\mathrm{a}$ & $2,4,14,18$ & b & 1 & $43.0^{\mathrm{bcd}}$ & $132.1^{\mathrm{bc}}$ & $10.4^{\text {cde }}$ \\
\hline$\gamma-45$ & $2^{*}$ & $6+8$ & $\mathrm{~h}$ & a & $\mathrm{a}$ & 1 & $36.6^{\text {cde }}$ & $87.6^{\text {cdef }}$ & $21.5^{\text {cde }}$ \\
\hline$\gamma-45$ & V & $6+8$ & d & f & b & 1 & $35.9^{\text {cde }}$ & $86.5^{\text {cdef }}$ & $27.5^{\mathrm{bc}}$ \\
\hline$\gamma-45$ & 1 & $6+8$ & $\mathrm{~h}$ & a & b & 1 & $35.5^{\text {cde }}$ & $56.1^{\text {def }}$ & $33.8^{\mathrm{ab}}$ \\
\hline$\gamma-45$ & Null & $6+8$ & $\mathrm{~h}$ & a & a & 2 & $33.7^{\text {cde }}$ & $103.4^{\mathrm{bcde}}$ & $21.0^{\text {cde }}$ \\
\hline$\gamma-45$ & 1 & $6+8$ & d & f & b & 1 & $33.5^{\text {cde }}$ & $74.6^{\text {cdef }}$ & $23.8^{\text {bcd }}$ \\
\hline$\gamma-45$ & Null & $20 x+20 y$ & a & a & $a$ & 8 & $33.3^{\text {cde }}$ & $113.5^{\mathrm{bcd}}$ & $21.9^{\text {cde }}$ \\
\hline$\gamma-42$ & Null & $7+8$ & $5^{*}$ & $8,9,13,16,18$ & b & 1 & $30.6^{\text {def }}$ & $82.5^{\text {cdef }}$ & $29.8^{\mathrm{bc}}$ \\
\hline$\gamma-45$ & Null & $13+16$ & $\mathrm{a}$ & $2,4,14,18$ & b & 1 & $30.0^{\mathrm{def}}$ & $81.4^{\text {cdef }}$ & $24.8^{\text {bcd }}$ \\
\hline$\gamma-45$ & 1 & $6+8$ & $\mathrm{~h}$ & a & $\mathrm{a}$ & 1 & $29.1^{\text {def }}$ & $57.0^{\text {def }}$ & $27.5^{\mathrm{bc}}$ \\
\hline$\gamma-45$ & Null & $20 x+20 y$ & $\mathrm{~h}$ & $\mathrm{a}$ & $\mathrm{a}$ & 1 & $28.6^{\text {def }}$ & $101.2^{\text {bcde }}$ & $20.1^{\text {cde }}$ \\
\hline$\gamma-42$ & Null & $6+8$ & $5^{*}$ & $\mathrm{~b}$ & b & 1 & $27.6^{\mathrm{def}}$ & $74.8^{\text {cdef }}$ & $26.2^{\mathrm{am}}$ \\
\hline$\gamma-45$ & $2^{*}$ & $6+8$ & $\mathrm{~h}$ & $\mathbf{a}$ & b & 1 & $27.4^{\mathrm{ef}}$ & $36.5^{\mathrm{f}}$ & $21.2^{\text {cde }}$ \\
\hline$\gamma-45$ & 2 & $13+16$ & $\mathrm{a}$ & $a$ & $\mathrm{~b}$ & 1 & $25.5^{\mathrm{ef}}$ & $58.2^{\text {def }}$ & $41.7^{\mathrm{a}}$ \\
\hline$\gamma-42$ & Null & $7+8$ & b & $\mathrm{b}$ & $\mathrm{a}$ & 1 & $23.5^{\mathrm{ef}}$ & $76.7^{\text {cdef }}$ & $21.5^{\text {cde }}$ \\
\hline$\gamma-44$ & Null & $20 x+20 y$ & $\mathrm{a}$ & $\mathbf{a}$ & b & 1 & $22.8^{\mathrm{ef}}$ & $68.2^{\text {def }}$ & $21.2^{\text {cde }}$ \\
\hline$\gamma$-Null & $2^{*}$ & $6+8$ & b & $\mathrm{i}$ & $\mathrm{a}$ & 1 & $21.6^{\mathrm{ef}}$ & $44.6^{\mathrm{ef}}$ & $26.4^{\mathrm{bc}}$ \\
\hline$\gamma-45$ & 1 & $20 x+20 y$ & $\mathrm{a}$ & $\mathbf{a}$ & b & 1 & $21.0^{\mathrm{ef}}$ & $62.7^{\mathrm{def}}$ & $33.6^{\mathrm{ab}}$ \\
\hline$\gamma-45$ & Null & $13+16$ & $\mathrm{a}$ & $a$ & $\mathrm{a}$ & 1 & $20.9^{\mathrm{ef}}$ & $85.7^{\text {cdef }}$ & $22.6^{\text {cde }}$ \\
\hline$\gamma-42$ & Null & $6+8$ & $5^{*}$ & $8,9,13,16,18$ & b & 1 & $20.8^{\text {ef }}$ & $34.7^{\mathrm{f}}$ & $25.6^{\mathrm{bcd}}$ \\
\hline$y-45$ & Null & $20 x+20 y$ & $\mathrm{a}$ & $2,4,14,18$ & b & 1 & $16.0^{f}$ & $55.0^{\text {def }}$ & $28.3^{\mathrm{bc}}$ \\
\hline ANOVA & & & & & & & $7.46^{* *}$ & $7.17^{* *}$ & $4.6^{* *}$ \\
\hline
\end{tabular}

$\left.{ }^{*}\right)=$ Mean values with the same letter are not significantly different $(\mathrm{p} \leq 0.05)$.

**: Significant at $1 \%$

Abbreviation: No = Number of varieties; SDSS = Sodium dodecyl sulphate test; MT = Mixing time; BDR = Breakdown resistance 
only took into account the variation of the B-LMW-GS loci, it can be seen that the proportion of variance explained by the model is greater. This highlights the importance of the HMW-GS loci on the quality parameters. The influence of gliadins on the quality parameters is smaller since most of the varieties possess the $\gamma-45$ gliadin. The multiple comparisons (Duncan) of mean quality parameters (Table 5) indicated that the best allelic combination of prolamins was also found in the variety 'Iride' (Tables 1 and 4). Good mean values were also produced by the prolamins of the cultivars 'Derbessi', 'Grécale', 'Recio Cañihueco' and 'Recio de Bienservida', as well as those of 'Khiar', 'Maali','Nasr' and 'Baidha' (Tables 1 and 5). In the last cultivar ('Baidha'), it is worth highlighting the contribution of the presence of the subunit $\mathrm{V}$ of the Glu-A1 locus (allele $o$ ), the new combination of bands 2, 4, 14, 18 of the Glu-B3 locus with the HMW-GS $6+8$ of the Glu-B1 locus and the B-LMW-GS alleles Glu-A3a and Glu-B2b to the good quality parameter values of SDSS, MT and BDR ( $43,0 \mathrm{~mm}, 132.1 \mathrm{~s}$ and $10.4 \%$, respectively).

It can be seen from Table 5 that the cultivars with B-LMW-GS allelic composition a a a (for the Glu-A3, Glu-B3 and Glu-B2 loci, respectively) when associated with the HMW-GS of the loci Glu$A 1$, Glu-B1, Null and $7+8$, have high mean values of SDSS and MT. By contrast, when this B-LMW-GS allelic composition is associated with HMW-GS of the loci Glu-A1, Glu-B1, Null and 20x $+20 \mathrm{y}$, the same quality parameters have low mean values, which are even lower when associated with the HMW-GS of the Null and $13+16$ and relatively high values of BDR. Similarly, the cultivars with the B-LMW-GS allelic composition $a$ a $b$, have high mean values of SDSS and MT and low value of BDR when associated with the HMW-GS of the loci Glu-A1, GLu-B1, Null and $6+8$, but low values of SDSS and MT and high value of BDR when they are associated with the HMW-GS of the Null and $20 \mathrm{x}+20 \mathrm{y}$ and also when associated with the HMW-GS of the loci Glu-A1, GLu-B1, 2•• and $13+16$. However, the association between the B-LMW-GS allelic composition aaa (for the Glu-A3, Glu-B3 and Glu-B2 loci, respectively) with the Null and $7+8$ HMW-GS (of the Glu-A1 and Glu-B1 loci, respectively), as well as with the Null and $20 x+20 y$ HMW-GS of the same loci, gave best resistance to breakdown (BDR) from the mixograph.

Finally, we should consider that a unified allelic nomenclature for genes expressing LMW-GS in the A and $B$ genomes of durum and bread wheat remains to be established, an effort already having been done for HMW-GS loci.

\section{Conclusion}

Landraces retain a wide genetic diversity for glutenin composition. They are a natural reservoir of alleles potentially useful to enhance and diversify gluten characteristics in durum wheat breeding programs.

Our results identified varieties with improved quality traits for use in durum breeding programs, particularly for gluten strength. A significant effect of the HMW and B-LMW-GS locus variation on the quality parameters was found. Although a small number of samples with rare alleles have been found, these results may be considered like an initiation. Lines obtained from crosses between the samples with "interesting" alleles and commercial varieties that have proven their high gluten strength, should be interesting for further work. Furthermore, taking into account the uncommon HMW-GS alleles seems to be interesting.

Moreover, it appeared that some uncommon alleles and combinations could have a significant contribution to gluten quality. However, LMW and HMW glutenin subunit combination give a discriminant criterion for selecting lines in breeding for durum wheat quality. Knowledge of the effect of these alleles on pasta quality will provide plant breeders a useful tool for selecting early generation lines that combine the best allelic combinations when breeding for quality. The use of the allelic combinations in the absence of a physical test for gluten strength is not recommended. This is because seasonal conditional variations could alter the molecular weight distribution of the gluten polymer resulting in lower gluten strength than expected for the specific glutenin allelic composition.

\section{Acknowledgements}

The Authors are grateful to Dr Belhaj-Salah Halim from the "Institut National des Grandes Cultures (INGC) in Tunisia who kindly provided seed material of the Tunisian varieties. This work was supported by Grant No. AGL 2012-38345 from the Ministerio de Economía y Competitividad in Spain.

\section{References}

Aguiriano, E., Ruiz, M., Fité, R., Carrillo, J.M., 2006. Analysis of genetic variability in a sample of the durum wheat (Triticum durum Desf.) Spanish collection based on gliadin markers. Genet. Resour. Crop Evol. 53, 1543-1552.

Aguiriano, A., Ruiz, M., Fité, R., Carrillo, J.M., 2008. Genetic variation for glutenin and gliadins associated with quality in durum wheat (Triticum turgidum L. ssp. turgidum) landraces from Spain. Span. J. Agric. Res. 6, 599-609.

Boggini, G. Pogna, N.E., 1989. The breadmaking quality and storage protein composition of Italian durum wheat. J. Cereal Sci. 9, 131-138.

Carrillo, J.M., Vázquez, J.F., Orellana, J., 1990. Relationships between gluten strength and proteins in durum wheat cultivars. Plant Breed. 104, 325-333.

Cherdouh, A., Khelifi, D., Carrillo, J.M., Nieto-Taladriz, M.T., 2005. The high and low molecular weight glutenin subunit polymorphism of Algerian durum wheat landraces and old cultivars. Plant Breed. 124, 338-342.

Dick, J.W., Quick, J.S., 1983. A modified screening test for rapid estimation of gluten strength in early generation durum wheat breeding lines. Cereal Chem. 60, 315-318.

DuCros, D.L., Wrigley, C.W., Hare, R.A., 1982. Prediction of durum wheat quality from gliadin-protein composition. Aust. J. Agr Res. 33, 297-302.

DuCros, D.L., 1987. Glutenin proteins and gluten strength in durum wheat. J. Cereal Sci. $5,3-12$.

Finney, K.F., Shogren, M.D., 1972. A ten-gram mixograph for determining and predicting functional properties of wheat flours. Bak. Dig. 46, 32-47.

Giraldo, P., Rodríguez-Quijano, M., Simón, C., Vázquez, J.F., Carrillo, J.M., 2010. Allelic variation in HMW glutenin in Spanish wheat landraces and their relationship with bread quality. Span. J. Agric. Res. 8, 1012-1023.

Lafiandra, D., Kasarda, D.D., 1985. One and two-dimensional (two pH) polyacrylamide gel electrophoresis in a single gel: separation of wheat proteins. Cereal Chem. 62, 314-319.

Lerner, S.E., Cogliatti, M., Ponzio, N.R., Seghezzo, M.L., Molfese, E.R., Rogers, W.J., 2004. Genetic variation for grain protein components and industrial quality of durum wheat cultivars sown in Argentina. J. Cereal Sci. 40, 161-166.

Liu, C.Y., Shepherd, K.W., Rathjen, A.J., 1996. Improvement of durum wheat pastamaking and breadmaking qualities. Cereal Chem. 73, 155-166.

Marchylo, B.A., Dexter, J.E., Clarke, F.R., Clarke, J.M., Perston, K.R., 2001. Relationship among bread making quality, gluten strength, physical dough properties and pasta cooking quality for some Canadian durum wheat genotypes. Can. J. Plant Sci. $81,611-620$.

Margiotta, B., Colaprico, G., D'Ovidio, R., Lafiandra, D., 1993. Characterisation of high $M_{r}$ subunits of glutenin by combined chromatographic (RP-HPLC) and electrophoretic separation and restriction fragment length polymorphism (RFLP) analyses of their encoding genes. J. Cereal Sci. 17, 221-236.

Martinez, M.C., Ruiz, M., Carrillo, J.M., 2005. Effects of different prolamin alleles on durum wheat quality properties. J. Cereal Sci. 41, 123-131.

Nazco, R., Peña, R.J., Ammar, K., Villegas, D., Crossa, J., Moragues, M., Royo, C., 2014. Variability in glutenin subunit composition of Mediterranean durum wheat germplasm and its relationship with gluten strength. J. Agric. Sci. 152, 379-393.

Nieto-Taladriz, M.T., Ruiz, M., Martinez, M.C., Vázquez, J.F., Carrillo, J.M., 1997. Variation and classification of B low-molecular weight glutenin subunit alleles in durum wheat. Theor. Appl. Genet. 95, 1155-1160.

Payne, P.I., Law, C.N., Mudd, E.E., 1980. Control by homologous group 1 chromosomes of the high molecular weight subunits of glutenin, a major protein of wheat endosperm. Theor. Appl. Genet. 58, 113-120.

Payne, P.I., Holt, L.M., Lawrence, C.J., Law, C.N., 1982. The genetics of gliadins and glutenin, the major storage proteins of the wheat endosperm. Plant Foods Hum. Nutr. 31, 229-241.

Payne, P.I., Jackson, E.A., Holt, L.M., 1984. The association between gliadin 45 and gluten strength in durum wheat varieties: a direct causal effect of the result of genetic linkage? J. Cereal Sci. 2, 73-81. 
Payne, P.I., Lawrence, G.J., 1983. Catalogue of alleles for the complex gene loci GluA1, Glu-B1 and Glu-D1 which code for high-molecular weight subunits of glutenin in hexaploid wheat. Cereal Res. Commun. 23, 95-101.

Rodríguez-Quijano, M., Lucas, R., Ruiz, M., Giraldo, P., Espi, A., Carillo, J.M., 2010. Allelic variation and geographical patterns of prolamins in the USDA-ARS khorasan wheat germplasm collection. Crop Sci. 50, 1-9.

Ruiz, M., Carrillo, J.M., 1993. Linkage relatioships between prolamin genes on chromosomes $1 \mathrm{~A}$ and $1 \mathrm{~B}$ of durum wheat. Theor. Appl. Genet. 87, 353-360.

Singh, N.K., Shepherd, K.W., Cornish, G.B., 1991. A simplified SDS-PAGE procedure for separating LMW subunits of glutenin. J. Cereal Sci. 14, 203-208.

Singh, N.K., Shepherd, K.W., 1988. Linkage mapping of the genes controlling endosperm proteins in wheat. 1. Genes on the short arms of group-1 chromosome. Theor. Appl. Genet. 75, 628-641.
Sissons, M.J., Batey, I.L., 2003. Protein and starch properties of some tetraploid wheats. Cereal Chem. 80, 468-475.

Sissons, M.J., Ames, N.P., Hare, R.A., Clarke, J.M., 2005. Relationship between glutenin subunit composition and gluten strength measurements in durum wheat. J. Sci. Food Agr 85, 2445-2452.

Vallega, V., Mello-Sampayo, T., 1987. Variation of high-molecular-weight glutenin subunits among cultivars of Triticum turgidum L. from Portugal. Euphytica 3 $755-762$.

Vazquez, J.F., Ruiz, M., Nieto-Taladriz, M.T., Albuquerque, M.M., 1996. Effects on gluten strength of low $\mathrm{Mr}$ glutenin subunits coded by alleles at the Glu-A3 and Glu-B3 loci in durum wheat. J. Cereal Sci. 24, 125-130. 